Structural Eng. / Earthquake Eng. Vol. 3. No. 2, 485s, October 1986/Discussion-Closure Japan Society of Civil Engineers (Proc. of JSCE No. 374/I-6)

\title{
A NON-ITERATIVE OPTIMUM DESIGN METHOD FOR CABLE-STAYED BRIDGES
}

(By Kunio TORII, Kiyohiro IKEDA and Tomihiko NAGASAKI)

Structural Eng./Earthquake Eng. Vol. 3, No.1, 103s 111s, October 1986

(Proc. of JSCE No.368/ I-5)

DiscussionBy Masaaki HOSHINO (Shin-Nippon Giken Co., Ltd)

The authors have presented an interesting approach toward optimum design method for cable-stayed bridges. The writer sees that the method is based on Eq. (17), which is derived from Eq. (16). The writer would like to point out that three terms in the parentheses of Eq. (17), $a_{i} \cdot \frac{N_{i}^{2}}{\sigma_{N a i}}, b_{i} \cdot \frac{M_{i}^{2}}{\sigma_{N a i}}$ and $d_{i}$, have different dimensions from each other, provided that coefficients, $a_{i}, b_{i}$ and $d_{i}$, in Eq. (17) are identical with those in Eq. (16). Therefore, the correctness of Eq. (17) seems to be questionable.

(Received May 15 1986)

Closure By Kunio TORII, Kiyohiro IKEDA and Tomihiko NAGASAKI

The authors sincerely appreciated the valuable academic comment offered by Mr. Masaaki Hoshino. We felt rewarded to know that our paper has drawn some interest but fully embarrassed to find a mistake in the paper.

The closure for this comment is as follows. As he mentioned, the variables $a_{i}, b_{i}$, and $d_{i}$ have different dimensions in Eqs. (16) and (17). They apparently are incorrect in this regard. In order to resolve this problem, the three variables in Eq. (17) should be replaced by $a_{i}^{*}, b_{i}^{*}$, and $d_{i}^{*}$, respectively. These two equations nonetheless have only conceptual meanings in the context so that this modification would not affect the remaining parts of paper.

(Received September 18 1986) 